S sciendo

\title{
Real Necessity: a Reply to Barnes
}

Bob Hale

University of Glasgow

Disputatio No. 8

November 2002

DOI: $10.2478 /$ disp-2002-0008

ISSN: 0873-626X 
Disputatio 13, November 2002

\section{REAL NECESSITY: \\ A REPLY TO BARNES}

Bob Hale

University of Glasgow

Gordon Barnes ${ }^{1}$ is in sympathy with my attempt ${ }^{2}$ to show that we must believe that there is such a thing as logical necessity — and in particular, that at least some rules of inference necessarily preserve truth - but contends that it involves an undesirable commitment to modal anti-realism, and in that sense fails to show that necessity is 'real', even if it succeeds in establishing its indispensability. In short, he likes my conclusion, but dislikes my argument for it. According to Barnes, that argument relies upon a premiss which he formulates as:

(RT) For any subject S, and for any rule of inference $\mathrm{R}$, if there is a proposition $p$ such that $\mathrm{R}$ fails to preserve truth under the supposition that $p$, then for some proposition $q$, it is possible for $\mathrm{S}$ to recognise that $\mathrm{R}$ fails to preserve truth under the supposition that $q$

Assuming, as he thinks reasonable ${ }^{3}$, that the variable $\mathrm{S}$ should be taken to range of beings with cognitive powers like our own, there are, he claims, just three ways in which one might try to justify (RT). One might argue (i) that the relevant fact about recognisability "is somehow entailed by the very nature of our cognitive powers" or (ii) that it is "an empirically discovered, contingent fact about us and our cognitive powers" or finally (iii) that it is "somehow entailed by the very nature of logical possibility and, correspondingly, of logical necessity". Barnes swiftly dismisses (i) on grounds of implausibility in the absence of further argument and (ii) as viciously circular for reasons akin to those for which attempts to justify induction by its past successes are usually thought to be so - (iii), he thinks, is the route a

\footnotetext{
${ }^{1}$ Barnes 2002.

${ }^{2}$ Hale 1999.

${ }^{3}$ I shall not dispute this assumption.
} 
Bob Hale

defender of my argument must follow. But he can do so, Barnes argues, only at the unacceptable cost of endorsing modal anti-realism - that is, as he describes it, the denial that logical possibility is an objective, mindindependent feature of the world.

I shall first explain why I do not believe Barnes has disclosed any good reason to think my argument uncongenial to a modal realist, and then comment briefly on some further questions prompted by his discussion.

\section{I}

The main point I wish to make in my defence - and, I think, the only point I strictly need to make - is that my argument does not, contrary to what Barnes supposes, require me to endorse (RT). Although the point is in essence simple enough, it will worthwhile to explain it more fully, since besides being liable to escape notice, it bears upon a further question I shall consider later. Barnes's belief that I am committed to (RT) is based entirely upon his reading of the following passage, requoted here in full for ease of reference:

If the sceptic's professed falsificationist attitude towards rules of inference is not to be empty, it requires us to think that, for any one of our rules $R$ which has thus far survived all attempts to envisage its failure, it is nevertheless conceivable that some circumstances $p$ should obtain, in which $\mathrm{R}$ would recognisably fail to be reliable. Falsificationism without the possibility of recognisable falsification is not worthy of serious consideration. (1999:32)

There would seem to be just two possibilities. Either Barnes thinks that (a) I expressly assert (RT) here or he thinks that (b) while I do not expressly assert (RT), something I do assert commits me to endorsing it. I take these in turn:

$\boldsymbol{R} \boldsymbol{e}$ (a) On the face of it, this is Barnes's view, since he actually claims that I "seem to be asserting" (RT). But this is fairly obviously wrong. The only part of the quoted passage which might, with any semblance of plausibility, be viewed as an expression of (RT) is "for any one of our rules R .... recognisably fail to be reliable". But, prescinding from the question whether (RT) correctly captures their import, there is clearly no assertion of (RT) here. My claim was a conditional one, of which these words constitute merely the consequent. The conditional claim was all I needed, because my argument was ad hominem, being directed specifically against a certain kind of sceptic - one who holds that no rules are necessarily truth-preserving, but that we don't need to believe that our rules are so in order justifiably to 
use them, because we can adopt a falsificationist attitude towards them (i.e. assume them to be truth-preserving — although not necessarily so - and continue to use them until and unless we find otherwise). In short, my claim was not that recognisable failure of each of our rules must be conceivable, only that if one is a falsificationist sceptic of this stripe, one must hold it to be so $^{4}$.

In fact, (RT) plainly does not capture the import of the words in question. For whilst those words are, in effect, a generalised conditional, just as (RT) is, they are equivalent to the quite different generalised conditional:

$\forall \mathrm{R}(\neg \exists p \exists \mathrm{S} \mathrm{S}$ recognises that $\mathrm{R}$ fails when $p \rightarrow \diamond \exists p \exists \mathrm{S} \mathrm{S}$ recognises that $\mathrm{R}$ fails when $p$ )

Since the generalised conditional which differs from this one only by replacing its antecedent by its contradictory:

$\forall \mathrm{R}(\exists p \exists \mathrm{S} \mathrm{S}$ recognises that $\mathrm{R}$ fails when $p \rightarrow \diamond \exists p \exists \mathrm{S} \mathrm{S}$ recognises that $\mathrm{R}$ fails when $p$ )

is but an instance of the schema: $\forall \mathrm{x}(\mathrm{Fx} \rightarrow \diamond \mathrm{Fx})$, which is valid in any reasonable (alethic) modal logic, it is a logical truth. These two conditionals together entail, and are each separately entailed by:

(Q) $\forall \mathrm{R} \diamond \exists p \exists \mathrm{S} S$ recognises that $\mathrm{R}$ fails when $p$

to which the first is, by suppression of the logically true second, logically equivalent. But $(\mathrm{Q})$ is clearly not logically equivalent to (RT). Minus the quantifiers binding R and S, (Q) corresponds fairly closely, not to (RT) as a whole, but to the consequent of the open conditional it embeds.

$\boldsymbol{R} \boldsymbol{e}$ (b) My last point might encourage the thought that Barnes would do better to claim that I am committed to endorsing (RT), even though I don't expressly assert it. So far as I can see, the only plausible way to defend this claim would be to maintain that my case for thinking that a falsificationist sceptic is committed to (Q) must appeal to (RT). Intuitively, the thought would have to be that this sceptic's commitment to $(\mathrm{Q})$ results from his claim that no rules are necessarily truth-preserving together with a general premiss to the effect that if a rule doesn't invariably preserve truth (i.e. there is some supposition under which it fails to do so), there must be some

\footnotetext{
${ }^{4}$ My actual words "requires us to think" were, therefore, potentially misleading, and may well have misled Barnes.
} 
Bob Hale

supposition under which it recognisably fails to preserve truth. More precisely, taking (RT) to be the requisite general premiss, the sceptic's commitment to (Q) would have to come about as follows. The sceptic asserts:

(S) $\forall \mathrm{R} \diamond \exists p$ R fails when $p$

But (RT) — interpreted with its embedded conditional as strict - holds. That is:

(RT*) $\forall \mathrm{R} \forall \mathrm{S} \square(\exists p$ R fails when $p \rightarrow \diamond \exists p \mathrm{~S}$ recognises that $\mathrm{R}$ fails when $p$ )

From (S) and (RT*), it follows (in S4, anyway) that $(\mathrm{Q})^{5}$.

The snag with this way of explaining the sceptic's commitment to (Q) is that it has me (but not the sceptic) asserting (RT*) and inferring the sceptic's commitment to (Q) from his endorsement (not mine) of (S). It is unclear why either of us should accept the conclusion, if we suppose that neither of us accepts both premisses. In fact, it should be clear that it matters not a jot whether $I$ assert $\left(\mathrm{RT}^{*}\right)$ - the argument will persuade the sceptic only if he does. So this attempt to saddle me with (RT) fares no better than the other. My reason for thinking the sceptic committed to (Q) was of a quite different kind, and so far as I can see, quite independent of any principle like (RT). My thought was quite simply that, whilst a falsificationist attitude towards some propositions - purported laws of nature, for example — might be defensible, it can be so only if one has some conception of what might count as a falsification of them. In particular, to claim that one is justified in continuing to accept and use a rule of inference for which one can provide no positive justification on the grounds that one is ready to abandon it, should one meet with a counter-example, but then refuse to accept even the possibility of recognisable counter-examples, is a sham - no more genuine falsificationism than a purportedly conditional promise, where one has no conception of how the condition under which one undertakes to honour the promise might be recognised to be fulfilled, is a genuine promise. My wife will rightly be completely unimpressed by my 'promise' to give up smoking if the number of electrons in the universe is odd. Similarly, and as I put it originally, falsificationism without the possibility of recognisable falsification is not worthy of serious consideration.

\footnotetext{
${ }^{5}$ The derivation is routine, the crucial step being of the form $\diamond A, \square(A \rightarrow \diamond B) \vdash \diamond B$. This is valid in S4. Of course, there is no valid step from $\diamond A, A \rightarrow \diamond B$ to $\diamond B-$ hence the need to construe (RT)'s embedded conditional as strict.
} 
If what I have said is right, there is no reason why a modal realist, in Barnes's sense, should avoid endorsing my original argument on the ground that it relies upon a premiss inconsistent with her realism. In particular, the argument does not rely upon (RT) (or ( $\left.\mathrm{RT}^{*}\right)$ ). For that reason, I had no need to consider whether it is true that (RT) is at best defensible only at the cost of modal anti-realism, i.e. of denying that propositions about what is possible or necessary are ever objectively and mind-independently true. Barnes believes so, because he believes that the only plausible way in which one might argue for (RT) appeals to the thesis that logical possibility is essentially recognisable, and that endorsing this thesis precludes one from regarding facts about logical possibility as objective and mind-independent. Since the issue, as I see it, is of some importance quite independently of the supposed rôle of (RT) in my argument, let me explain why I am not persuaded that this is so.

Niceties of formulation aside, what (RT) asserts is that if a rule of inference fails to preserve truth, it must recognisably fail to do so. This gloss should call to mind a quite general thesis, not restricted to matters modal, to which anti-realists of a certain kind - anti-realists, in Dummett's sense, about truth and meaning in general - appear to be committed, vis. the thesis that every truth is, at least in principle, knowable - i.e. $\forall p(p \rightarrow \diamond \mathrm{K} p)^{6}$. Obviously (RT) does not entail the general knowability thesis and might be maintained on grounds independent of any generalised semantic anti-realism - perhaps of the specific kind Barnes suggests. Equally obviously ${ }^{7}$, the knowability thesis entails not only (RT), but also the thesis that possibility is essentially recognisable ${ }^{8}$. So one could argue for (RT) without appeal to any thesis specifically about modality. But more importantly, if the latter is

\footnotetext{
6 ' $\mathrm{K}$ ' may be read as ' $\exists \mathrm{S} \exists \mathrm{t} \mathrm{S}$ knows at $\mathrm{t}$ that'. For present purposes, we can set aside questions about the range of values of the bound variables $S$ and $t$, of which it is probably necessary to take account in discussing - as I cannot do here - the wellknown objection to the thesis that it entails that every truth is (actually) known. But it is worth remarking that if an anti-realist is committed to the thesis, she should probably assert its necessitation.

Assuming, as I do, that (RT*) adequately captures the content of (RT), and the knowability thesis is taken in its necessitated form: $\square \forall p(p \rightarrow \diamond \mathrm{K} p)$.

${ }^{8}$ Which is just a special case of the knowability thesis. For this reason, it seems to me that Barnes is mistaken in thinking that the essential recognisability of possibility can only be secured by taking possibility to be a 'function of our disposition or tendency to recognise it as such'.
} 
Bob Hale

objectionable because it conflicts with the objectivity and mindindependence of matters modal, then that is equally an objection to the knowability thesis and hence to general semantic anti-realism. So if Barnes is right in his claim that the recognisability of possibility thesis is objectionable on just such grounds, general semantic anti-realism stands refuted.

Some might welcome such a conclusion. But it is, surely, too hastily drawn if reached by this route. Barnes is right to tie modal realism to the objectivity and mind-independence of modal truths, and right too, in my view, to take at least the second of these things to be best explicated in terms of the general idea that what is true is suitably independent of what we know or believe or tend to believe. But there is room to disagree about just how the notion of independence is to be understood and what kind and degree of independence is required. A realist in Dummett's sense can be seen as setting the standard extremely high — objective, mind-independent truths are truths which may obtain without there being any possibility, even in principle, of our recognising them. Barnes may be commending a simlarly exacting standard, when he suggests that the only alternative to conceiving of logical possibility as a "function of our disposition or tendency to recognise it as such" is to see it as "entirely mind-independent". But to set the standard this high is arguably to set it too high, at least if it is a quite general standard that is being proposed. For there are cases in which no such exacting standard is or can be met, where we have little tendency to think we are, therefore, no longer concerned with objective, mind-independent matters many ordinary arithmetic truths are effectively decidable and so, by their very nature, cannot obtain independently of all possibility, even in principle, of their being known to do so, and the same plausibly goes for simple statements about the observable features of middle-sized two- and threedimensional objects. So there is a case for thinking that somewhat less should be required for objectivity and mind-independence than the Dummettian realist offers. At the other extreme, the minimum requirement would seem to be that truth should be independent of our actual knowledge or belief $^{9}$ - i.e. that for it to be objectively and mind-independently true that $p$, it must at least be true that even if we do know or believe that $p$, it would still have been true that $p$, had we no knowledge or belief on the matter. A stronger condition would require that truth be independent, not just of what we do know or believe, or would know or believe were conditions other than they actually are, but of what we can or could in practice come to know. And perhaps there are other conditions which should be required for

\footnotetext{
${ }^{9}$ Hence the potentially lethal character of the threat posed by the objection mentioned in note 6 .
} 
objectivity, having to do with the possibility of intractable or nonnegotiable disagreement. I cannot pursue these questions here. It would, however, clearly be unwise to assume that there are simply no respectable notions of mind-independence and objectivity available to one who requires either possibility in particular or truth in general to be, in principle, recognisable.

Bob Hale

Dept of Philosophy

University of Glasgow

Glasgow G12 8QQ

B.Hale@philosophy.arts.gla.ac.uk

\section{References}

Barnes, Gordon, 2002. Hale's Necessity: It's Indispensable, but is it Real? Disputatio 13:3-10.

Hale, Bob. 1999. On Some Arguments for the Necessity of Necessity. Mind 108:23-52. 